\title{
Effect of iron overload on endothelial cell calcification and its mechanism
}

\author{
Lili Zhao ${ }^{1}$, Ning Yang ${ }^{2}$, Yanqiu Song ${ }^{1}$, Hailong Si $^{2}$, Qin Qin ${ }^{2}$, Zhigang Guo ${ }^{3}$ \\ ${ }^{1}$ Tianjin Institute of Cardiovascular Disease, Tianjin Chest Hospital, Tianjin, China; ${ }^{2}$ Department of Cardiology, Tianjin Chest Hospital, Tianjin, \\ China; ${ }^{3}$ Department of Cardiovascular Surgery, Tianjin Chest Hospital, Tianjin, China \\ Contributions: (I) Conception and design: L Zhao, N Yang; (II) Administrative support: Q Qin, Z Guo; (III) Provision of study materials or patients: \\ Y Song, H Si; (IV) Collection and assembly of data: L Zhao, N Yang, Y Song, H Si; (V) Data analysis and interpretation: L Zhao, N Yang; (VI) \\ Manuscript writing: All authors; (VII) Final approval of manuscript: All authors. \\ Correspondence to: Qin Qin. Department of Cardiology, Tianjin Chest Hospital, Taierzhuang South Road No. 261, Jinnan District, Tianjin 300222, \\ China. Email: tjchqinqin@163.com; Zhigang Guo. Department of Cardiovascular Surgery, Tianjin Chest Hospital, Taierzhuang South Road No. \\ 261, Jinnan District, Tianjin 300222, China. Email: Zhigangguo@yahoo.com.
}

Background: Vascular calcification is related to many diseases. Iron has a certain relationship with endothelial cells and vascular calcification. The purpose of this study was to assess the effect of iron overload on endothelial cell calcification and related mechanisms through cell experiments.

Methods: Human umbilical vein endothelial cells were treated with different concentrations of $\mathrm{FeSO}_{4}$ (50, 100, 150, and $200 \mu \mathrm{M})$, and deferoxamine (DFO) and ferrostatin. Alkaline phosphatase activity, malondialdehyde (MDA) level, reactive oxygen species (ROS) level, and lipid superoxidation after $\mathrm{FeSO}_{4}$ treatment were assessed. Alizarin red staining was used to observe calcium deposition. Quantitative polymerase chain reaction (qPCR) and western blot were adopted to examine the expression of calcification markers, iron metabolism-related factors, apoptosis pathway-related factors and ferroptosis markers. The TUNEL method was employed to detect cell apoptosis.

Results: $\mathrm{FeSO}_{4}$ of $100 \mu \mathrm{M}$ significantly promoted the occurrence of cell ferroptosis, increased the levels of MDA and ROS, and decreased the ratio of glutathione (GSH) or glutathione disulfide (GSSG) and the expression level of glutathione peroxidase (GPX4). The addition of DFO and ferrostatin significantly modified the effects of $\mathrm{FeSO}_{4}$. Calcium deposition was most obvious in the cells treated with $100 \mu \mathrm{M} \mathrm{FeSO}_{4}$. $\mathrm{FeSO}_{4}$ significantly upregulated Runt-related transcription factor 2 (RUNX2) and Bone morphogenetic protein 2 (BMP2), ferritin heavy chain (FTH) and ferritin light chain (FTL), and downregulated Matrix Gla Protein (MGP) and divalent metal transporter 1 (DMT1). The results also showed that $\mathrm{FeSO}_{4}$ induced cell apoptosis by TUNEL method. The elevated Bcl2-associated death protein (Bad) and Bcl2-associated $\mathrm{X}$ protein $(\mathrm{Bax})$ and the reduction in $\mathrm{Bcl}-2$, $\mathrm{p}-\mathrm{Bad}, \mathrm{p}-\mathrm{AKT}$, and $\mathrm{t}-\mathrm{AKT}$ were found. DFO and ferrostatin significantly reduced the iron-induced calcification and apoptosis of endothelial cells. DFO significantly increased the expression level of Bcl-2, and reduced the expression level of Bad.

Conclusions: Iron overload contributes to the process of endothelial cell calcification by inducing apoptosis and ferroptosis. Iron chelators and ferroptosis inhibitors alleviate endothelial cell apoptosis, ferroptosis, and calcification induced by iron overload.

Keywords: Iron overload; endothelial cell; calcification; apoptosis; ferroptosis

Submitted Aug 30, 2021. Accepted for publication Nov 16, 2021.

doi: $10.21037 / \mathrm{atm}-21-5666$

View this article at: https://dx.doi.org/10.21037/atm-21-5666 


\section{Introduction}

Vascular calcification mainly involves arteries and can occur in any part of the human body. The aorta, coronary arteries, and peripheral arteries are the most commonly involved vessels. Due to the high density of calcified tissues, they are easily located using imaging examinations $(1,2)$. Many studies found that vascular calcification is related to a variety of diseases. In the past, it was thought that vascular calcification was beneficial to local plaque stability. However, subsequent studies increasingly demonstrated that most vascular calcifications are related to adverse events and are not conducive to the treatment of local revascularization, because they increase the difficulty of passing balloons and stents and dilate blood vessels, and thus cause difficulty in treatment and poor prognosis (3-7). The mechanism of vascular calcification is relatively complicated, which is mainly related to genetics, osteogenic factors and related cell phenotype transformation, calcium and phosphorus metabolism imbalance, and the imbalance between vascular calcification promoting factors and inhibitors (8). Many previous studies found that iron was closely related to vascular calcification (9). However, the results of the research are not consistent and may be related to different research settings (10).

In mammals, iron is an important element for maintaining the normal function of cells. It participates in several key biological processes, including the production of adenosine triphosphate (ATP), the transport of oxygen, and the synthesis of DNA (11). The maintenance of iron homeostasis is regulated by many factors, including the absorption, storage, and elimination of iron. Some specific transport systems and membrane carriers are critical to the maintenance of iron homeostasis (12). Transferrin (Tf) and transferrin receptor 1 (TfR1) are the main iron uptake proteins, and cells absorb iron mainly through the Tf-TfR1 pathway (13). Most of the plasma iron is tightly bound to Tf, thereby shielding the redox activity of $\mathrm{Fe}^{3+}$. Subsequently, iron-Tf complexity merge with TfR1 on the cell surface and take up this complex through endocytosis. Once inside the cell, $\mathrm{Fe}^{3+}$ dissociates from $\mathrm{Tf}$ and is converted to $\mathrm{Fe}^{2+}$ by ferric reductase six-transmembrane epithelial antigen of prostate 3 (STEAP3) (14). Ferritin is an important storage protein of iron in the cytoplasm, and its expression level is regulated by the concentration of iron in the cell (15). Divalent metal transport (DMT1) and ferroportin (FPN) play an important role in the absorption and export of iron ions (15).
Many factors, such as excessive iron supplementation and genetic mutation, can lead to excessive iron in cells $(16,17)$. Excess iron and $\mathrm{H}_{2} \mathrm{O}_{2}$ can generate a large amount of reactive oxygen species (ROS) through the Fenton reaction, which promotes the production of lipid peroxides in cells and promotes cell death (18). Iron overload can induce the damages of many organ functions, leading to arrhythmias and cardiac fibrosis, increasing the risk of infection, causing liver and kidney damage and inducing osteoporosis (15). In addition, some reports have found that iron overload is related to calcification of valvular interstitial cells, vascular smooth muscle cells $(9,19)$. It is well known that endothelial cells play a crucial role in cardiovascular disease. Studies have shown that endothelial cells themselves can obtain osteogenic differentiation potential through endothelialmesenchymal transition (EndMT) and can also promote osteogenic transformation of vascular smooth muscle cells (VSMCs) and vascular calcification by releasing signal molecules, cytokines, vesicles and by inducing angiogenesis $(20,21)$. However, there are no studies to investigate that whether iron overload can cause endothelial calcification. Based on this, we carried out this study to observe the effect of iron overload on endothelial cell calcification and related mechanisms through cell experiments. We present the following article in accordance with the MDAR checklist (available at https://dx.doi.org/10.21037/atm-21-5666).

\section{Methods}

\section{Experimental methods}

\section{Cell culture}

Human umbilical vein endothelial cells (HUVECs, ATCC CRL-1730 ${ }^{\mathrm{TM}}$ ) were cultured in standard culture medium, including: Dulbecco's modified Eagle's medium/ F12 (DMEM/F12, Thermo Fisher, Waltham, MA, USA), $10 \%$ fetal bovine serum (FBS), $100 \mathrm{U} / \mathrm{mL}$ penicillin, and $100 \mathrm{mg} / \mathrm{mL}$ streptomycin, and the environment was controlled at $37{ }^{\circ} \mathrm{C}$ and $5 \% \mathrm{CO}_{2}$. To induce cell calcification, the cells were cultured with calcification medium containing DMEM/F12, 10\% FBS, and $10 \mathrm{mM} \beta$-glycerophosphate (Sigma-Aldrich, St. Louis, MO, USA) for 14 days. The medium was changed every 2 days. To assess the effect of iron on calcification, 50-200 $\mu \mathrm{mol} / \mathrm{L} \mathrm{FeSO}_{4}$ (Sigma, USA) was added to the standard medium for 14 days (19). Iron deficiency was induced by incubating the cells with $100 \mu \mathrm{mol} / \mathrm{L} \mathrm{FeSO}_{4}$ and $100 \mu \mathrm{mol} / \mathrm{L}$ DFO (Sigma-Aldrich, St. Louis, MO, USA) for 14 days. $1 \mu \mathrm{mol} / \mathrm{L}$ of ferroptosis 
inhibitor ferrostatin were added for 2 hours, and then $100 \mu \mathrm{mol} / \mathrm{L} \mathrm{FeSO}_{4}$ was added for 14 days, and the medium was changed every 2 days. When studying the mechanism of ferroptosis, the effects were generally observed after 3 days.

\section{Cell viability assay}

Cell Counting Kit-8 (CCK-8, Yeasen, Shanghai, China) was used to detect cell viability. According to the kit instructions, the cells were seeded into a 96 -well plate at a density of $1 \times 10^{4}$ cells/well and treated with different concentrations of $\mathrm{FeSO}_{4}$ for 24 and 48 hours. Then $10 \mu \mathrm{L}$ of CCK-8 reagent were added to each well and allowed to incubate the cells at $37^{\circ} \mathrm{C}$ for 2 hours. A microplate reader (BioTex, Thousand Oaks, CA, USA) was used to measure the absorbance at $450 \mathrm{~nm}$.

\section{Alizarin red S staining}

Alizarin red S staining was used to assess calcium deposition. HUVECs were seeded in 6-well plates at a concentration of $2 \times 10^{5} / \mathrm{mL}$. On the second day, $10 \mathrm{mM}$ $\beta$-glycerophosphate or $100 \mu \mathrm{mol} / \mathrm{L} \mathrm{FeSO}_{4}$ (with or without DFO) were added to the standard medium for 14 days. During staining, cells were washed twice with phosphate buffered saline (PBS), fixed with $4 \%$ paraformaldehyde (PFA) at room temperature for 10 minutes, washed 3 times with deionized water, washed with $1 \%$ Alizarin Red (pH 4.2, Solarbio, Beijing, China), and incubated at $37^{\circ} \mathrm{C}$ for 20 minutes. Deionized water was used to remove excess dye. A Nikon (Tokyo, Japan) inverted microscope was used to observe and photograph the cells.

\section{Alkaline phosphatase (ALP) activity assay}

The cells were seeded in a 6 -well plate at a density of $2 \times 10^{5}$ cells/well. The treatment of the cells was identical to that described above. After 14 days, the cells were washed twice with PBS and lysed with inhibitor-free lysis buffer (Beyotime Institute of Biotechnology, Jiangsu, China). According to the kit instructions, the Alkaline Phosphatase Detection Kit (Beyotime Institute of Biotechnology, Jiangsu, China) was used to detect ALP activity. Absorbance at $405 \mathrm{~nm}$ was read with a microplate reader. The ALP activity was calculated using a standard curve and standardized according to the protein concentration.

\section{Prussian blue staining}

According to the instructions, Prussian Blue Iron Staining Kit (Solarbio, Beijing, China) was used to determine cellular iron deposition. The cells were fixed with $4 \%$ paraformaldehyde (PFA) for 20 minutes, and washed twice with tap water and twice with deionized water. Then the cells were incubated with Perls stain for 30 minutes at room temperature.

\section{ROS measurement}

ROS Assay Kit (Beyotime Institute of Biotechnology, Jiangsu, China) was used to detect the level of ROS in cells. After the cells were seeded in a 6-well plate, $100 \mu \mathrm{mol} / \mathrm{L}$ $\mathrm{FeSO}_{4}$ (with or without $100 \mu \mathrm{mol} / \mathrm{L}$ DFO/1 $\mu \mathrm{mol} / \mathrm{L}$ ferrostatin) were added for 3 days, and the fluorescent probe DCFH-DA was loaded according to the instruction manual (1:4,000 dilution). After $20 \mathrm{~min}$, a Nikon (Tokyo, Japan) fluorescent inverted microscope was used to observe and photograph of cells.

\section{Lipid peroxidation assay}

Image-iT Lipid Peroxidation Kit (Thermo Fisher, Waltham, MA, USA) and Lipid Peroxidation Malondialdehyde (MDA) Assay Kit (Beyotime Institute of Biotechnology, Jiangsu, China) were used to detect the level of intracellular lipid superoxidation. The cell processing method is the same as above. The Image-iT Lipid Peroxidation Kit is based on BODIPY 581/591 C11 reagent and is a sensitive fluorescent reporter for lipid peroxidation. Flow cytometry detection was performed according to the instruction manual. The MDA Assay Kit uses a color reaction based on the reaction of MDA and thiobarbituric acid (TBA) to produce a red product, which is then used to quantitatively detect MDA in cell lysates using colorimetry and operated according to the instructions. The microplate reader reads the absorbance at $532 \mathrm{~nm}$.

\section{GSH/GSSG assay}

Glutathione (GSH)/glutathione disulfide (GSSG) Assay Kit (Beyotime Institute of Biotechnology, Jiangsu, China) was used to detect the content of GSH/GSSG in cells. The cell processing method was used as described above, and according to the instructions the absorbance at $412 \mathrm{~nm}$ was read with a microplate reader.

\section{Process}

\section{Observation of the effect of iron overload on} endothelial cell calcification

The CCK- 8 experiment was used to detect the effect of different concentrations of iron on the viability of 
endothelial cells: cells were placed onto 96-well plates, and the next day cells were treated with $50,100,150$, and $200 \mu \mathrm{M} \mathrm{FeSO}{ }_{4}$ for 24 and $48 \mathrm{~h}$, and the effects of different concentrations of $\mathrm{FeSO}_{4}$ on cell viability were observed. To detect the effect of iron overload on alkaline phosphatase activity, cells were placed onto a 6-well plate and treated with $10 \mathrm{mM} \beta$-glyceride phosphate (positive control), and 50 and $100 \mu \mathrm{M} \mathrm{FeSO}$ for 14 days. Cells were collected and lysed, the supernatant was collected, and the Alkaline Phosphatase Activity Detection Kit (Beyotime, Jiangsu, China) was used to detect the alkaline phosphatase activity in the cell lysate of each group. Alizarin red staining was used to detect the effect of iron on endothelial cell calcification: the cells were passaged to a 6-well plate, and the cells were treated with $10 \mathrm{mM} \beta$-glycerol phosphate (positive control), $50 \mu \mathrm{M}$, $100 \mu \mathrm{M} \mathrm{FeSO}_{4}$ for 14 days, and stained with Alizarin Red (Solarbio, Beijing, China) to observe the calcium deposits in the cells. To detect the effect of iron on the expression of calcification marker messenger RNA (mRNA) in endothelial cells, the cells were placed onto 6-well plates and treated with $10 \mathrm{mM} \beta$-glycerol phosphate (positive control) and $100 \mu \mathrm{M} \mathrm{FeSO}$ for 14 days. The cells were collected, RNA was extracted with TRIzol (Life Technologies, Carlsbad, CA, USA), and RNA was reverse-transcribed into circular DNA (cDNA) using a reverse transcription kit. Quantitative polymerase chain reaction ( $\mathrm{qPCR}$ ) was used to observe the mRNA expression of calcification markers RUNX2, BMP2, and MGP. To detect the effect of iron on the expression of endothelial cell calcification marker protein, cells were placed onto 6-well plates and treated with $10 \mathrm{mM}$ $\beta$-glyceride phosphate (positive control) and $100 \mu \mathrm{M} \mathrm{FeSO}_{4}$ for 14 days. Cells were collected, protein was extracted with radioimmunoprecipitation assay (RIPA) reagent, and the protein concentration was determined using the bicinchoninic acid assay (BCA) method. Then the protein expression of RUNX2 and BMP2 was measured using western blot.

\section{Effect of iron overload on iron metabolism-related factors of endothelial cells}

Prussian blue staining was used to detect the effect of iron on the iron deposition of endothelial cells: cells were placed onto a 6-well plate and on the next day treated with $10 \mathrm{mM} \beta$-glyceride (positive control) and $100 \mu \mathrm{M} \mathrm{FeSO}_{4}$ for 14 days, and the Prussian Blue Iron Staining Kit (Solarbio, Beijing, China) was used to assess iron deposition in the cells. To detect the effect of iron overload on the mRNA expression of iron metabolism-related factors in endothelial cells, cells were placed onto 6-well plates and treated with $10 \mathrm{mM} \beta$-glycerol phosphate (positive control) and $100 \mu \mathrm{M}$ $\mathrm{FeSO}_{4}$ for 14 days. Cells were collected, RNA was extracted with TRIzol (Life Technologies, Carlsbad, CA, USA), and RNA was reverse-transcribed into cDNA using a reverse transcription kit. qPCR was used to detect the mRNA expression of iron metabolism-related factors ferritin heavy chain (FTH), ferritin light chain (FTL), and divalent metal transporter 1 (DMT1). To detect the effect of iron overload on the protein expression of iron metabolism-related factors in endothelial cells, cells were placed onto 6-well plates, and cells were treated with $10 \mathrm{mM} \beta$-glyceride phosphate (positive control) and $100 \mu \mathrm{M} \mathrm{FeSO}_{4}$ for 14 days. Cells were collected, protein was extracted with RIPA reagent, and the protein concentration was determined using the BCA method. The protein expression of the iron metabolism-related factors FT and DMT1 was assessed using western blot.

\section{Role of iron overload in endothelial cell calcification}

The TUNEL staining method was used to assess the effect of iron on endothelial cell apoptosis: cells were placed inside the chamber and treated with $10 \mathrm{mM} \beta$-glyceride (positive control) and $100 \mu \mathrm{M} \mathrm{FeSO}$ for 7 days on the next day, and the TUNEL Staining Kit (US Evervbright Inc., Jiangsu, China) was used to observe cell apoptosis. To detect the effect of iron overload on the mRNA expression of endothelial cell apoptosis pathway-related factors, cells were placed onto 6-well plates and treated with $10 \mathrm{mM}$ $\beta$-glyceride (positive control) and $100 \mu \mathrm{M} \mathrm{FeSO}_{4}$ for 7 days. The cells were collected, RNA was extracted with TRIzol (Life Technologies, Carlsbad, CA, USA) and reversetranscribed into cDNA using a reverse transcription kit. qPCR was used to detect the mRNA expression of apoptosis pathway-related factors Bcl-2, Bad, and Bax. To detect the effect of iron overload on the protein expression of iron metabolism-related factors in endothelial cells, cells were placed onto 6-well plates and treated with $10 \mathrm{mM} \beta$-glycerol phosphate (positive control) and $100 \mu \mathrm{M} \mathrm{FeSO}_{4}$ for 7 days. Cells were collected, protein was extracted with RIPA reagent, and the protein concentration was determined using the BCA method. The protein expression of apoptosis pathway-related factors p-AKT, t-AKT, Bcl-2, Bad, p-Bad, and Bax was assessed using western blot.

\section{Effect of inhibition of iron overload on endothelial cell calcification}

Alizarin red staining was used to detect the effect of inhibitors on iron-induced endothelial cell calcification: cells 
were placed onto a 6-well plate, and the next day the cells were treated with $100 \mu \mathrm{M} \mathrm{FeSO}, \mathrm{FeSO}_{4}+\mathrm{DFO}$ and $\mathrm{FeSO}_{4}$ + ferrostatin (Fers) for 14 days, and the calcium deposits in the cells were assessed using Alizarin Red (Solarbio, Beijing, China) staining. To detect the effect on the mRNA expression of endothelial cell calcification marker, the cells were placed onto a 6-well plate and treated with $100 \mu \mathrm{M} \mathrm{FeSO}_{4}, \mathrm{FeSO}_{4}+\mathrm{DFO}$ and $\mathrm{FeSO}_{4}+$ Fers for 14 days. The cells were collected, RNA was extracted with TRIzol (Life Technologies, Carlsbad, CA, USA), and RNA was reverse-transcribed into cDNA using a reverse transcription kit. qPCR was used to detect the mRNA expression of calcification marker RUNX2. Cells were placed onto 6-well plates, and $100 \mu \mathrm{M} \mathrm{FeSO}, \mathrm{FeSO}_{4}+\mathrm{DFO}$ and $\mathrm{FeSO}_{4}+$ Fers were used to treat cells for 14 days. The cells were collected, the protein was extracted with RIPA reagent, and the protein concentration was determined using the BCA method. The effect of the protein expression of calcification marker RUNX2 was observed using western blot.

\section{Deferoxamine's effects on endothelial cell apoptosis}

The TUNEL staining method was used to observe the effect of DFO on endothelial cell apoptosis. The cells were placed into the chamber and treated with $100 \mu \mathrm{M}$ $\mathrm{FeSO}_{4}$ and $\mathrm{FeSO}_{4}+\mathrm{DFO}$ on the next day for 7 days, and a TUNEL staining kit was used to observe cell apoptosis. To detect the effect of deferoxamine on the mRNA expression of the related factors of endothelial cell apoptosis induced by iron overload, the cells were placed onto 6-well plates and treated with $100 \mu \mathrm{M} \mathrm{FeSO}{ }_{4}$ and $\mathrm{FeSO}_{4}+\mathrm{DFO}$ for 7 days. The cells were collected, RNA was extracted with TRIzol (Life Technologies, Carlsbad, CA, USA), and RNA was reverse-transcribed into cDNA using a reverse transcription kit. qPCR was used to assess the mRNA expression of the apoptosis pathway-related factors Bcl-2 and Bad. To detect the effect of deferoxamine on the expression of proteins related to the apoptosis of endothelial cells induced by iron overload, the cells were placed onto a 6-well plate and treated with $100 \mu \mathrm{M} \mathrm{FeSO}_{4}$ and $\mathrm{FeSO}_{4}+$ DFO for 7 days. The cells were collected, the protein was extracted with RIPA reagent, and the protein concentration was determined by the BCA method. Western blot was used to observe the protein expression of apoptosis pathwayrelated factors Bcl-2, Bad, and p-Bad.

Role of ferroptosis in the process of iron overloadinduced cell calcification

$\mathrm{FeSO}_{4}$ of $100 \mu \mathrm{M}, \mathrm{FeSO}_{4}+\mathrm{DFO}$ or $\mathrm{FeSO}_{4}+$ ferrostatin were used to treat the cells for 3 days. To observe the effects of iron overload on the level of lipid oxidation in cells, the cells were placed onto a 6 -well plate, the cells were treated as described above for 3 days, and The Image-iT Lipid Peroxidation Kit (Thermo Fisher, Waltham, MA, USA) and the MDA detection kit (Beyotime Institute of Biotechnology, Jiangsu, China) was used to detect the level of lipid superoxidation in the cells. To investigate the effect of iron overload on the level of Glutathione (GSH)/glutathione disulfide (GSSG) in the cells, the cells were placed onto a 6-well plate, the cells were treated as described above, and the GSH/GSSG Detection Kit was used (Beyotime Institute of Biotechnology, Jiangsu, China). To examine the effect of iron overload on the level of reactive oxygen species in cells, the cells were placed onto a 6-well plate, the cells were treated as described above for 3 days, and the ROS Detection Kit (Beyotime Institute of Biotechnology, Jiangsu, China) was used. To detect the effects of iron overload on the mRNA expression of ferroptosis marker, cells were placed onto a 6-well plate, and after 7 days of treatment of the cells according to the above method, RNA was extracted with TRIzol (Life Technologies, Carlsbad, CA, USA), and RNA was reversetranscribed into cDNA using a reverse transcription kit. qPCR was used to assess the mRNA expression level of ferroptosis marker GPX4. To detect the effect of iron overload on the expression of ferroptosis marker protein, cells were placed onto a 6-well plate, the cells were treated for 3 days according to the above method, the cells were collected, the protein was extracted with the RIPA reagent, and the protein concentration was determined using the BCA method. The protein level of ferroptosis marker GPX4 was observed using western blot.

\section{Statistical analysis}

SPSS22.0 statistical software was used to perform statistical analyses. The data were normally distributed and were described using means (standard deviations), and the $t$-test or F-test was used for comparisons between groups. $\mathrm{P}<0.05$ indicates that differences were statistically significant.

\section{Results}

\section{Effect of iron overload on endothelial cell calcification}

Cells were treated with 50, 100, 150, and $200 \mu \mathrm{M} \mathrm{FeSO}_{4}$ for $48 \mathrm{~h}$. As the concentration increased, cell viability decreased 
(Figure 1A). The results showed that the ALPase activity of the $10 \mathrm{mM} \beta$-glyceride phosphate (positive control), and the 50 and $100 \mu \mathrm{M} \mathrm{FeSO}$ treatment groups increased (Figure 1B). Calcium deposition in the cells treated with $100 \mu \mathrm{M} \mathrm{FeSO}_{4}$ was the most obvious (Figure 1C). The results of qPCR and western blot showed that $100 \mu \mathrm{M} \mathrm{FeSO}$ significantly upregulated the mRNA and protein expression levels of RUNX2 and BMP2 and downregulated the mRNA expression levels of Matrix Gla Protein (MGP) (Figure 1D-1I).

\section{Effect of iron overload on the iron metabolism-related factors of endothelial cells}

The results of Prussian blue staining showed that after treatment with $100 \mu \mathrm{M} \mathrm{FeSO}$ for 14 days, iron deposition increased significantly (Figure $2 A$ ). The results of qPCR showed that $100 \mu \mathrm{M} \mathrm{FeSO}$ treatment significantly upregulated the mRNA expression levels of FTH and FTL, while it downregulated the mRNA expression levels of divalent metal transporter 1 (DMT1) (Figure 2B-2D). Western blot results showed that iron overload $(100 \mu \mathrm{M}$ $\mathrm{FeSO}_{4}$ treatment) significantly upregulated the expression level of ferritin and downregulated the protein expression of DMT1 (Figure 2E-2G).

\section{Effect of iron overload on endothelial cell apoptosis}

TUNEL staining results showed that $100 \mu \mathrm{M} \mathrm{FeSO}$ significantly promoted cell apoptosis (Figure $3 A$ ). The results of qPCR showed that $100 \mu \mathrm{M} \mathrm{FeSO}{ }_{4}$ significantly upregulated the mRNA expression levels of Bad and Bax and downregulated the mRNA expression levels of Bcl-2 (Figure $3 B-3 D)$. Western blot results show that iron overload $\left(100 \mu \mathrm{M} \mathrm{FeSO}_{4}\right)$ significantly reduced the protein expression level of p-Bad, Bcl-2, p-AKT, and t-AKT, and simultaneously increased the protein expression level of Bax. The effect was not significant, but it significantly reduced the ratio of $\mathrm{p}-\mathrm{Bad} / \mathrm{t}-\mathrm{Bad}$ and had no significant effect on the ratio of p-AKT/t-AKT (Figure 3E-37).

\section{Use of inbibitors reduces the occurrence of cell calcification}

Alizarin red staining test results showed that DFO and ferrostatin significantly reduced iron-induced endothelial cell calcification (Figure 4A). At the same time, the results of PCR and western blot showed that DFO and ferrostatin significantly reduced the increase in the expression of ironinduced calcification marker RUNX2 (Figure 4B-4D).

\section{Iron chelator affects endothelial cell calcification by inhibiting cell apoptosis}

TUNEL staining results showed that DFO significantly reduced endothelial cell apoptosis induced by iron overload (Figure $5 A$ ). At the same time, after adding DFO, the expression level of Bcl-2 was significantly higher than that of the Fe group, and the expression level of Bad was significantly lower than that of the Fe group (Figure $5 B-5 E$ ). However, the effect on the ratio of p-Bad/t-Bad did not show a statistically significant difference (Figure $5 F$ ).

\section{Iron participates in the occurrence of cell calcification by inducing cell ferroptosis}

To investigate whether the iron overload induces the ferroptosis in the endothelial cells, lipid superoxidation by the BODIPY 581/591 C11 reagent and MDA test, ROS, GSH/GSSG and GPX4 expression were measured. And results showed that the levels of lipid superoxidation and ROS in cells treated with $100 \mu \mathrm{M} \mathrm{FeSO}$ were significantly increased, the ratio of GSH/GSSG was decreased, and the expression level of GPX4 was decreased. Iron chelator and ferrostatin significantly reduced the level of MDA and ROS, increased the ratio of GSH/GSSG (Figure 6A-6D), and upregulated the expression level of GPX4 (Figure 6E-6G).

\section{Discussion}

This study proved that iron overload reduced the viability of endothelial cells and induced calcium deposition and calcification of endothelial cells. In this process, iron overload increased the expression of FTH and FTL and decreased the expression of DMT1. At the same time, iron overload promoted endothelial cell apoptosis, which led to changes in the expression of apoptosis-related proteins. Iron chelator alleviated the apoptosis and calcification of endothelial cells induced by iron overload. Further studies found that iron overload was involved in the process of calcification and that it is also related to the induction of cell ferroptosis. As far as we know, this study reveals for the first time that iron overload leads to endothelial cell calcification, and that it is the first study to elucidate possible mechanisms at the cellular and molecular levels.

Calcification can occur in both veins and arteries, but the clinical focus is mainly on arterial calcification. Arterial calcification can be roughly divided into two types. One type occurs in the atherosclerosis of the heart valve and 
A

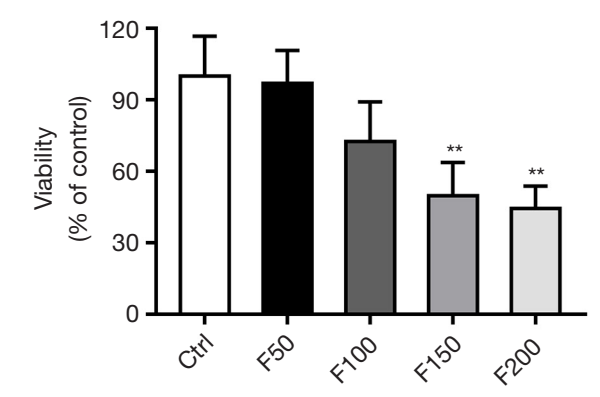

C

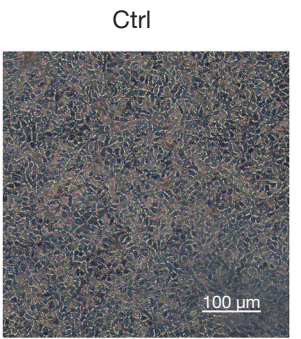

D

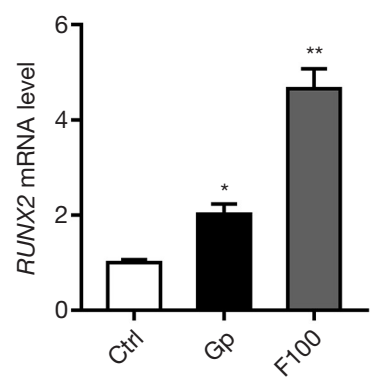

G

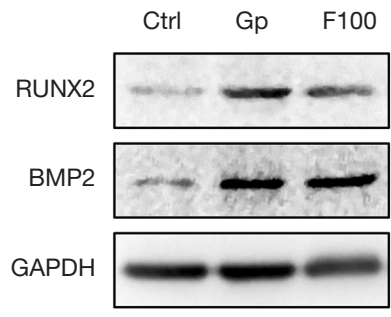

B

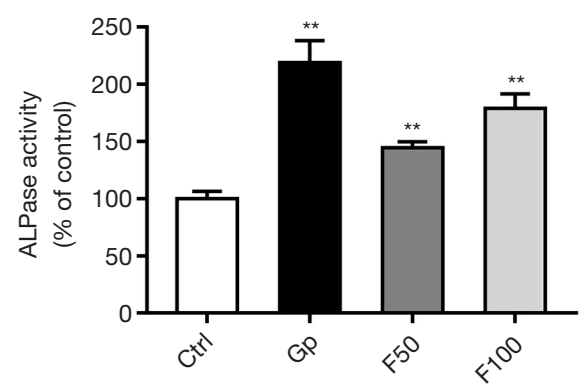

Gp

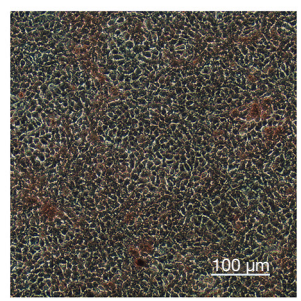

E

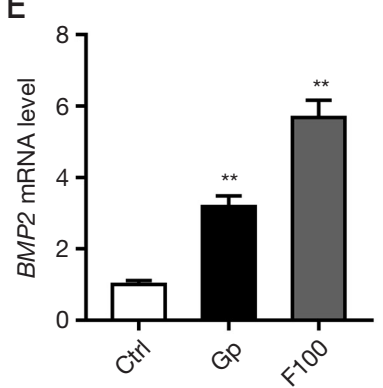

$\mathrm{H}$

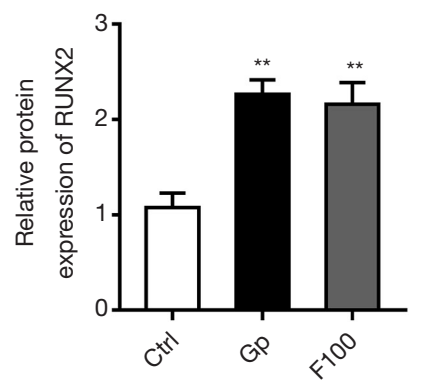

F50

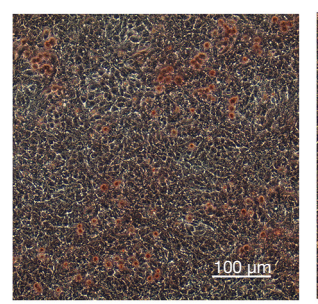

$\mathrm{F}$
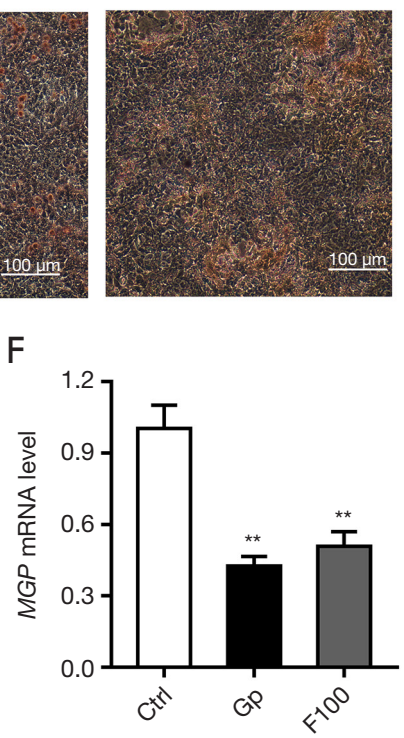

I

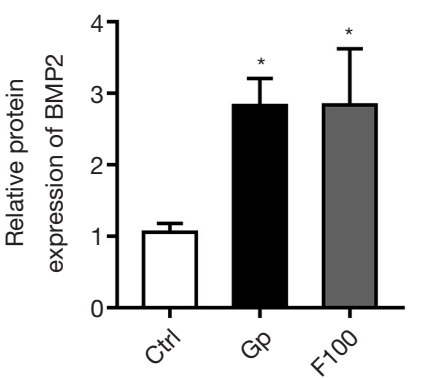

Figure 1 Effect of iron overload on endothelial cell calcification. (A) Cells are treated with 50, 100, 150, and $200 \mu \mathrm{M} \mathrm{FeSO} \mathrm{H}_{4}$ for $48 \mathrm{~h}$. As the concentration increased, cell viability decreased. (B) Alkaline Phosphatase Activity Detection Kit (Beyotime, Jiangsu, China) was used to detect the alkaline phosphatase activity in the cell lysate of each group. The activities of $10 \mathrm{mM} \beta$-glyceride phosphate (positive control),

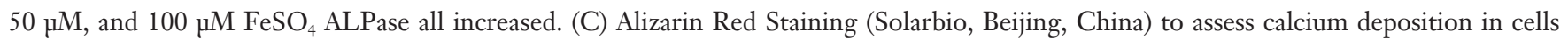
(×100). (D-F) quantitative polymerase chain reaction (qPCR) experiment to observe the mRNA expression of calcification markers RUNX2, BMP2, and MGP. (G-I) Western blot to observe the protein expression of calcification markers RUNX2 and BMP2. Ctrl: cells not treated in any way; Gp: $10 \mathrm{mM} \beta$-glyceride phosphate added; F50: $50 \mu \mathrm{M} \mathrm{FeSO}$ treated cells; F100: $100 \mu \mathrm{M} \mathrm{FeSO}{ }_{4}$ treated cells; F150: $150 \mu M$ $\mathrm{FeSO}_{4}$ treated cells; F200: $200 \mu \mathrm{M} \mathrm{FeSO}$ treated cells. *, compared with Ctrl, $\mathrm{P}<0.05$; **, compared with Ctrl, $\mathrm{P}<0.001$. ALPase, Alkaline Phosphatase; RUNX2, Runt-related transcription factor 2; BMP2, Bone morphogenetic protein 2; MGP, Matrix Gla Protein. 
A
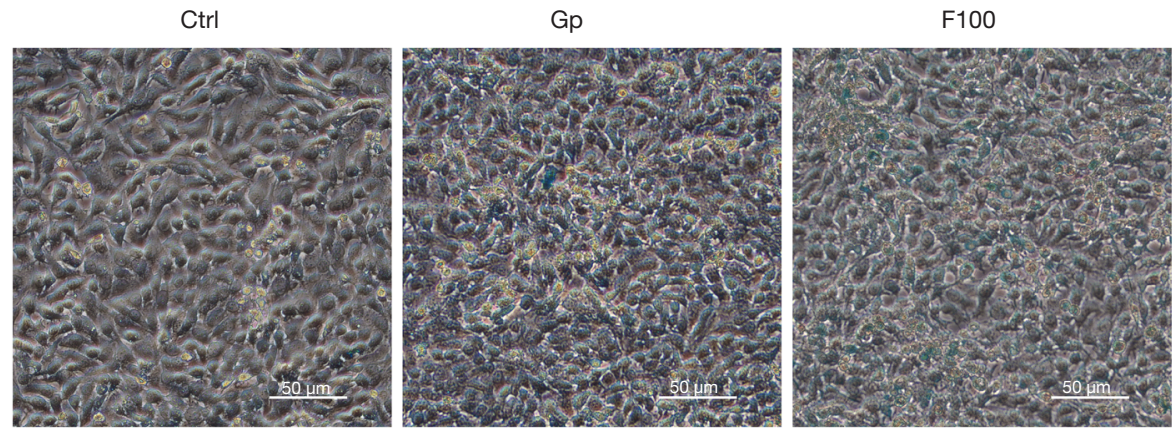

B

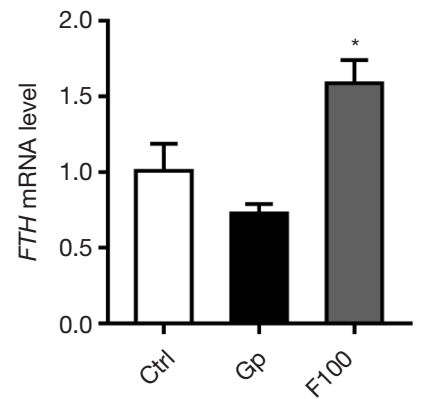

$E$

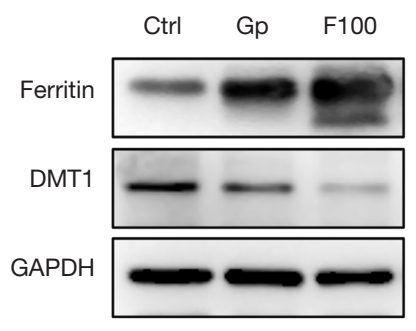

C

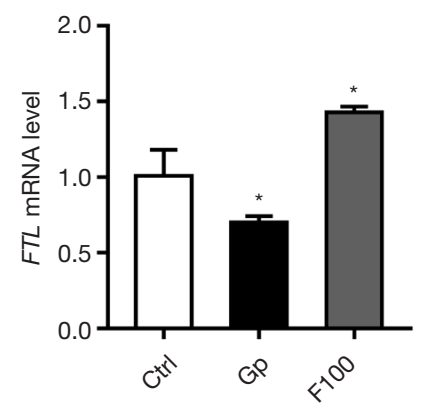

$\mathrm{F}$

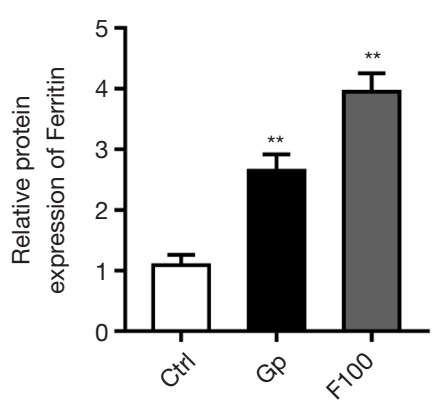

D

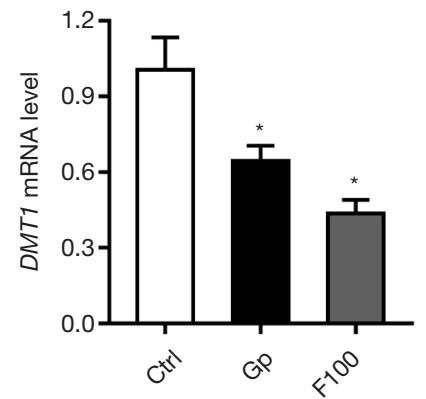

G

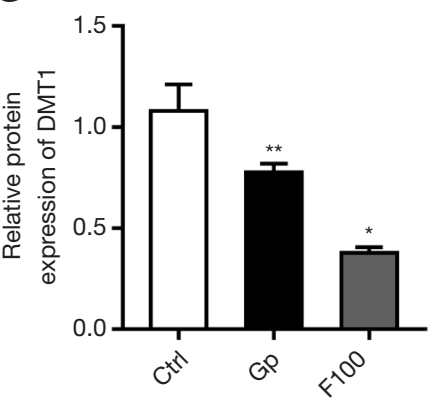

Figure 2 Effect of iron overload on the iron metabolism-related factors of endothelial cells. (A) Prussian blue staining was used to detect the effect of iron on the iron deposition of endothelial cells. After the cells were treated with $100 \mu \mathrm{M} \mathrm{FeSO}{ }_{4}$ for 14 days, iron deposition increased significantly ( $\times 200)$. (B-D) qPCR assessed the effect of iron overload on the expression of FTH, FTL, and DMT1 mRNA. (E-G) Western blot assessed the effect of iron overload on the protein expression of ferritin and DMT1. Ctrl: cells not treated in any way; Gp: $10 \mathrm{mM} \beta$-glyceride phosphate added; F100: $100 \mu \mathrm{M} \mathrm{FeSO}_{4}$ treated cells. * , compared with Ctrl, $\mathrm{P}<0.05$; ${ }^{* *}$, compared with Ctrl, $\mathrm{P}<0.001$. qPCR, quantitative polymerase chain reaction; FTH, ferritin heavy chain; FTL, ferritin light chain; DMT1, divalent metal transporter 1; mRNA, messenger RNA.

the arterial intima. It is related to macrophages, lipids, and arterial smooth muscle cells, including intimal calcification, media calcification, and aortic valve calcification and calcification defense (22). The other is the calcification of the arterial media due to the mineralization of elastic fibers in end-stage kidney disease or diabetes (23). To date, studies have shown that both intimal and media calcification increase the risk of adverse events, including coronary ischemic events, diastolic dysfunction after left ventricular hypertrophy, and heart failure (24-29). Bourantas et al. found that coronary artery calcification increased the risk of all-cause death [hazard ratio (HR): 1.33 ; 95\% CI: 1.00-1.77; $\mathrm{P}=0.047]$ and the risk of fatal myocardial infarction (HR: 1.23; 95\% CI: 1.02-1.49; $\mathrm{P}=0.031$ ) (24). In an 8-year follow- 
A

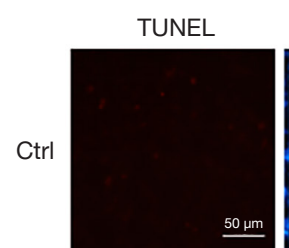

Gp

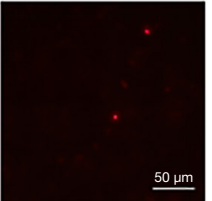

F100

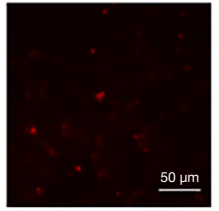

D

G

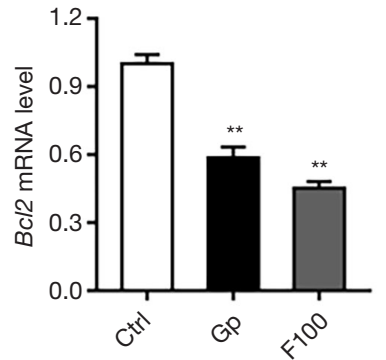

E

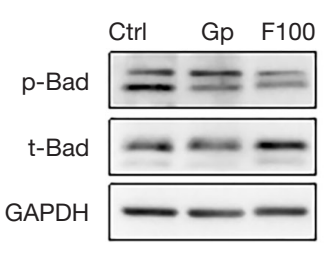

$\mathrm{H}$
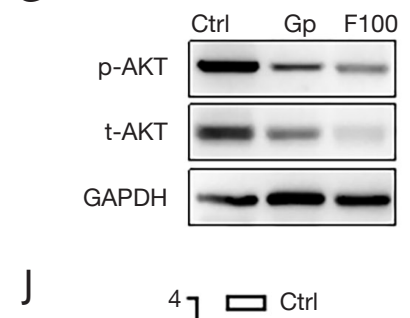

DAPI
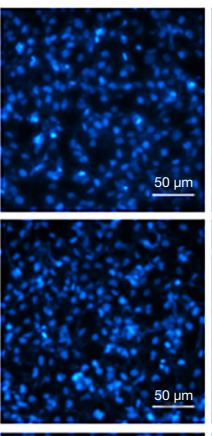
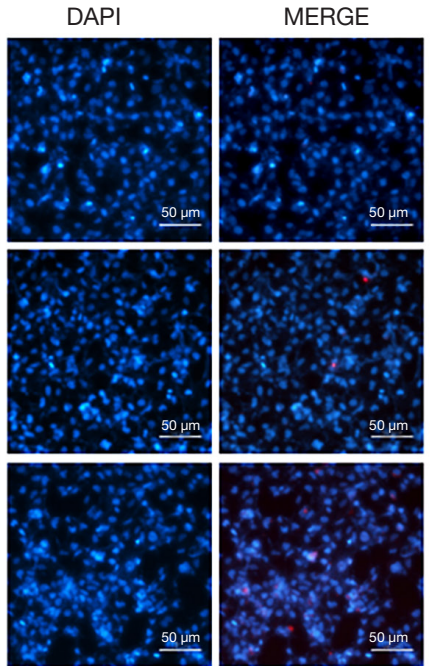

B

H 1.2

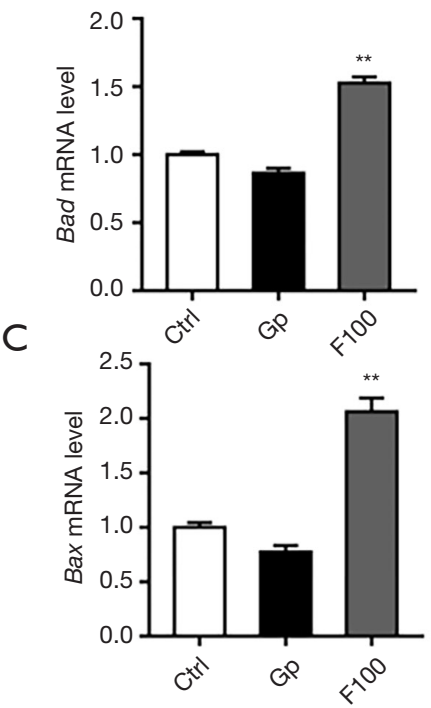

F
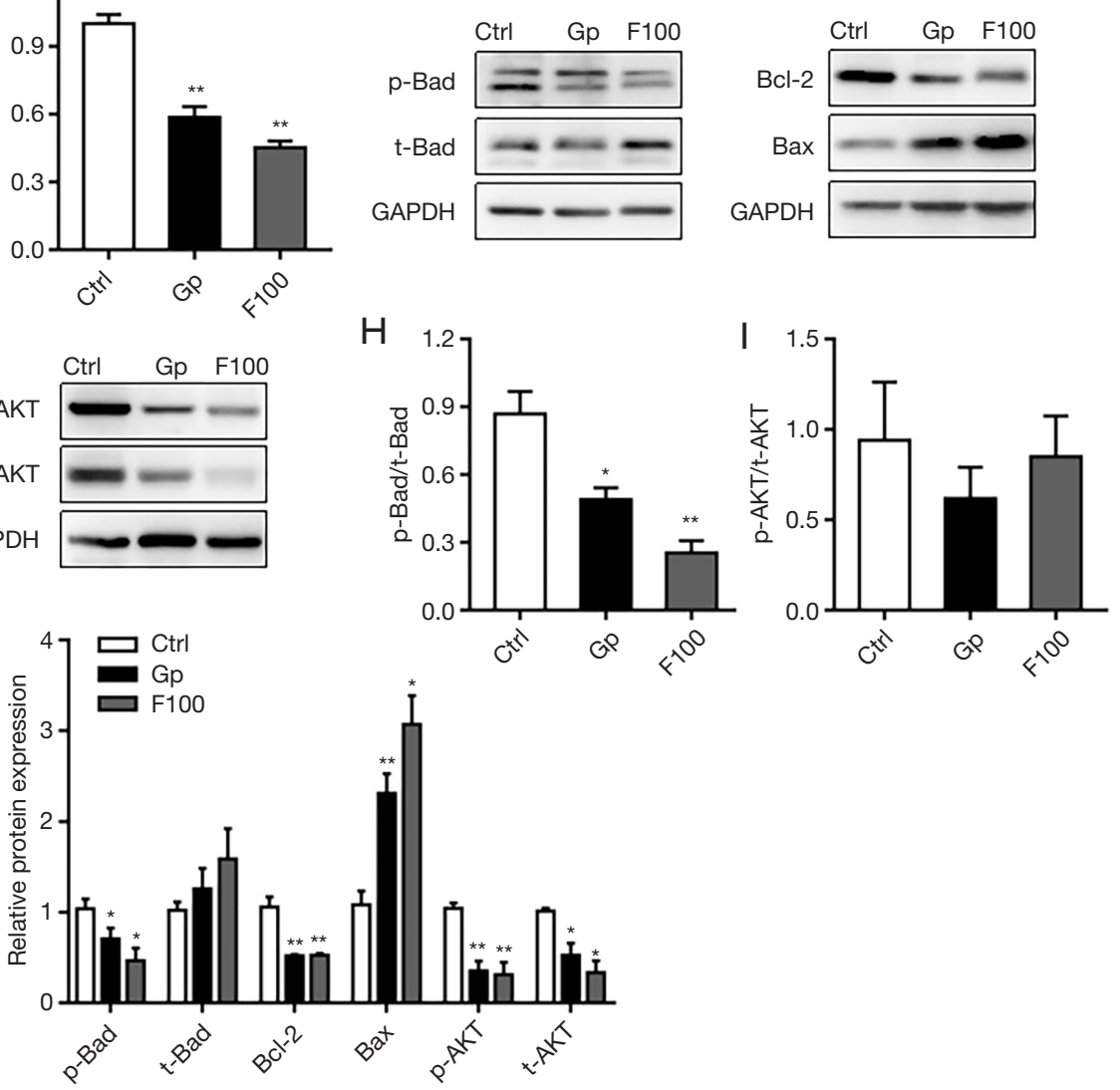

Figure 3 Effect of iron overload on endothelial cell apoptosis. (A) TUNEL staining method to observe the effect of iron on endothelial cell apoptosis, $100 \mu \mathrm{M} \mathrm{FeSO}_{4}$ promotes apoptosis (×200). (B-D) qPCR to assess the effect of iron overload on the expression of Bad, Bax, Bcl-2 mRNA. (E-J) Western blot assessed the effect of iron overload on the protein expression of Bad, p-Bad, Bax, Bcl-2, p-AKT, and t-AKT. Ctrl: cells not treated in any way; Gp: $10 \mathrm{mM} \beta$-glyceride phosphate added; F100: $100 \mu \mathrm{M} \mathrm{FeSO}{ }_{4}$ treated cells. *, compared with Ctrl, $\mathrm{P}<0.05$; **, compared with Ctrl, $\mathrm{P}<0.001$. Bad, Bcl2-associated death protein; Bax, Bcl2-associated X protein; Bcl2, B-cell lymphoma-2; AKT(PKB), protein kinase B; qPCR, quantitative polymerase chain reaction; mRNA, messenger RNA. 
A
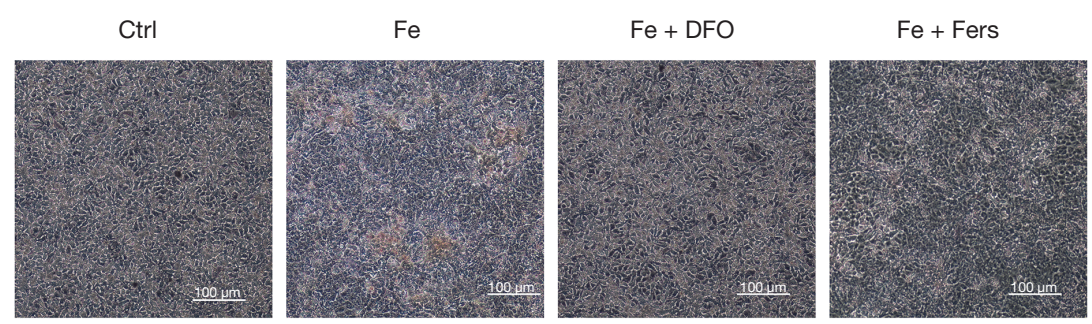

B

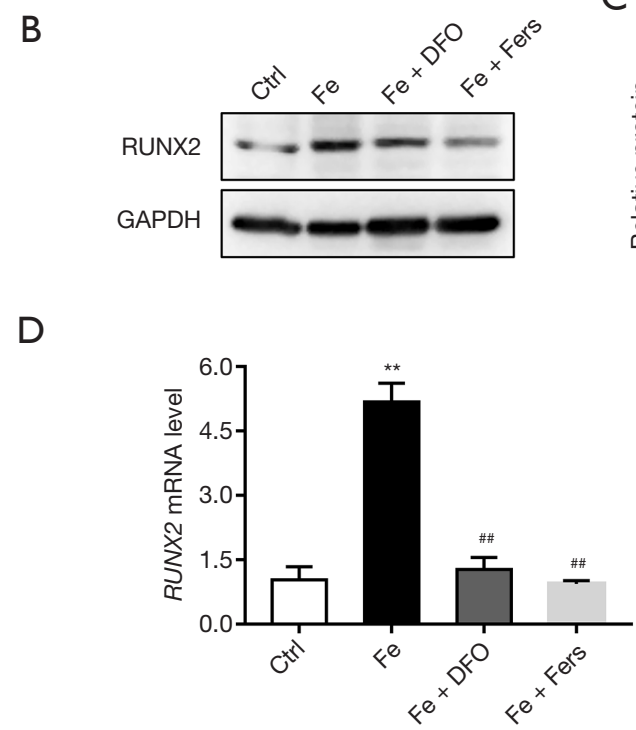

C

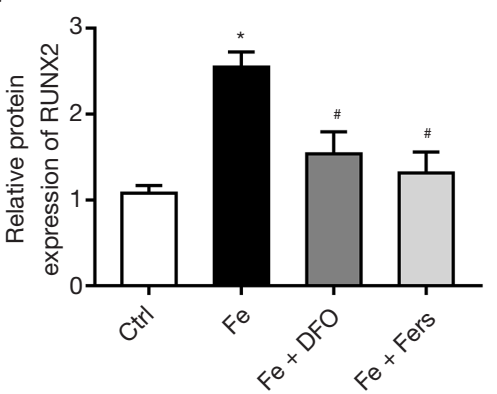

Figure 4 Ferroptosis inhibitors reduce the occurrence of cell calcification. (A) Alizarin red staining to detect the effect of iron chelator and ferroptosis inhibitor ferrostatin on iron-induced endothelial cell calcification $(\times 100)$. (B,C) Western blot to assess the effect of iron chelator and ferroptosis inhibitor on the protein expression of calcification marker RUNX2. (D) PCR experiment to assess the effect of iron chelator and ferroptosis inhibitor on the expression of RUNX2 mRNA. Ctrl: cells without any treatment; Fe: $100 \mu \mathrm{M} \mathrm{FeSO}_{4}$ treated cells; $\mathrm{Fe}+\mathrm{DFO}$ : $100 \mu \mathrm{M} \mathrm{FeSO}_{4}$ + iron chelator treated cells; $\mathrm{Fe}+$ Fers: $100 \mu \mathrm{M} \mathrm{FeSO}_{4}$ + ferroptosis inhibitor ferrostatin treated cells. *, compared with Ctrl, $\mathrm{P}<0.05$; **, compared with Ctrl, $\mathrm{P}<0.001$; " , compared with $\mathrm{Fe}, \mathrm{P}<0.05$; ${ }^{\text {\#\# }}$, compared with $\mathrm{Fe}, \mathrm{P}<0.001$. RUNX2, Runt-related transcription factor 2; PCR, polymerase chain reaction; mRNA, messenger RNA.

up study, Niu et al. found that abdominal aortic calcification increased the risk of all-cause death (HR $=2.089 ; 95 \%$ CI: $1.089-4.042 ; \mathrm{P}=0.029)$ and cardiovascular death risk in peritoneal dialysis patients (HR $=4.660$; 95\% CI: $1.852-$ $11.725 ; \mathrm{P}=0.001)$, and that femoral artery calcification also increased the associated risk (26). Studies have also found that breast artery calcification increased the risk of allcause death and cardiovascular death (25). The mechanism of vascular calcification is very complicated and is not fully understood at present. It is generally believed that blood vessel or valve cells, especially VSMCs, quiescent valve interstitial cells (VICs), and resident fibroblasts, are the main cells behind the osteogenic process that leads to calcification of blood vessels and heart valves. It is generally believed that atherosclerosis is due to endothelial dysfunction that causes lipoproteins to stay in the arteries where the laminar flow is disturbed by arterial branches (30). The inflammatory and immune cells, including macrophages, $\mathrm{T}$ cells, and mast cells, are recruited in atherosclerotic area and produce pro-inflammatory mediators and enzymes (31). Macrophages oxidize and catabolize lipoproteins in the arterial wall. The oxidized lipoproteins will cause the death of macrophages and eventually merge into the necrotic core. At the same time, VSMCs migrate to the intima and promote the formation of a fibrous cap dominated by collagen (32). The calcification of atherosclerotic plaque is a healing response to inflammatory activity and also leads to the transformation of osteogenic VSMCs $(33,34)$. Recently 
A
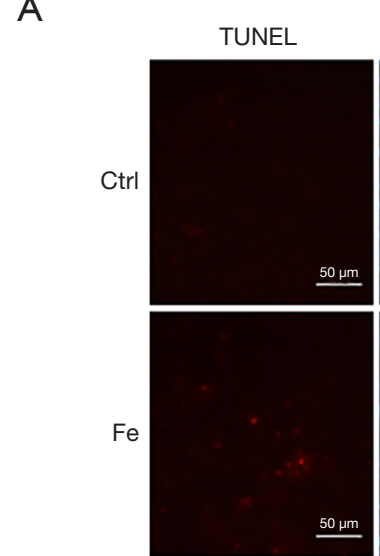

$50 \mu \mathrm{m}$

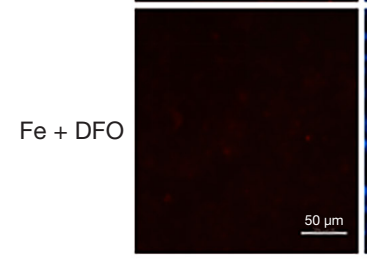

$\mathrm{D}$

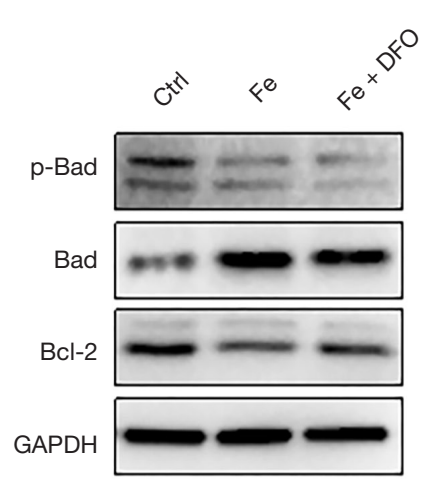

$\mathrm{F}$

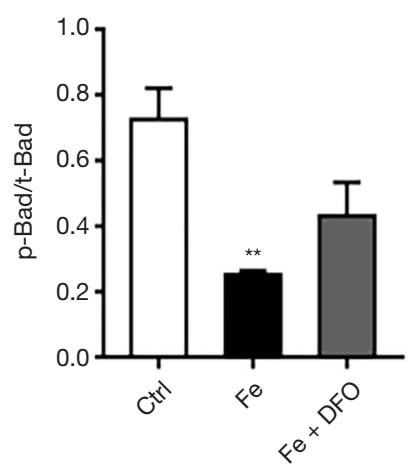

B
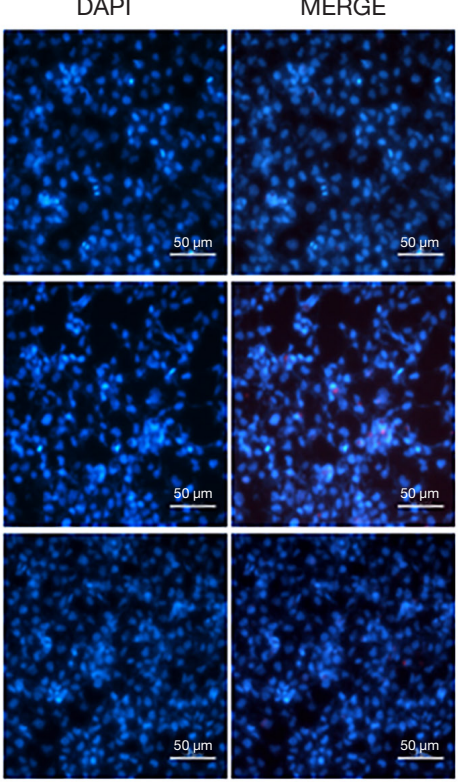

$\mathrm{E}$

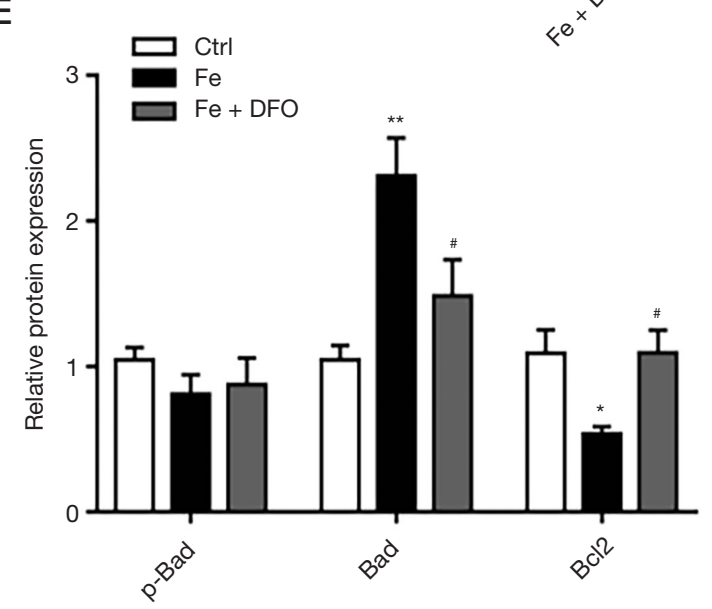

Figure 5 Use of iron chelator affects endothelial cell calcification by inhibiting apoptosis. (A) TUNEL staining method to observe the effect of iron chelator on endothelial cell apoptosis $(\times 200)$. (B,C) The effect of iron chelator on the expression of apoptosis related factors Bad and Bcl-2 mRNA. (D,E) Iron chelator on cell apoptosis, influence of related factors Bad, p-Bad, Bcl2 protein expression. (F) Ratio of p-Bad/ t-Bad in different groups. Ctrl: cells not treated; Fe: $100 \mu \mathrm{M} \mathrm{FeSO}_{4}$ treated cells; $\mathrm{Fe}+\mathrm{DFO}: 100 \mu \mathrm{M} \mathrm{FeSO} \mathrm{O}_{4}$ + iron chelator treated cells. *, compared with Ctrl, $\mathrm{P}<0.05$; **, compared with Ctrl, $\mathrm{P}<0.001$; ", compared with $\mathrm{Fe}, \mathrm{P}<0.05$; ;", compared with $\mathrm{Fe}, \mathrm{P}<0.001$. Bad, Bcl2associated death protein; Bax, Bcl2-associated X protein; Bcl2, B-cell lymphoma-2; AKT(PKB), protein kinase B; mRNA, messenger RNA. 
A

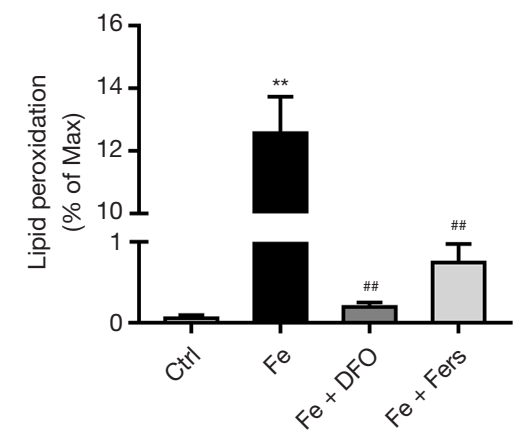

C

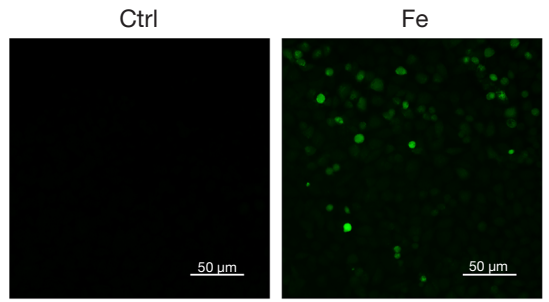

D

$\mathrm{F}$
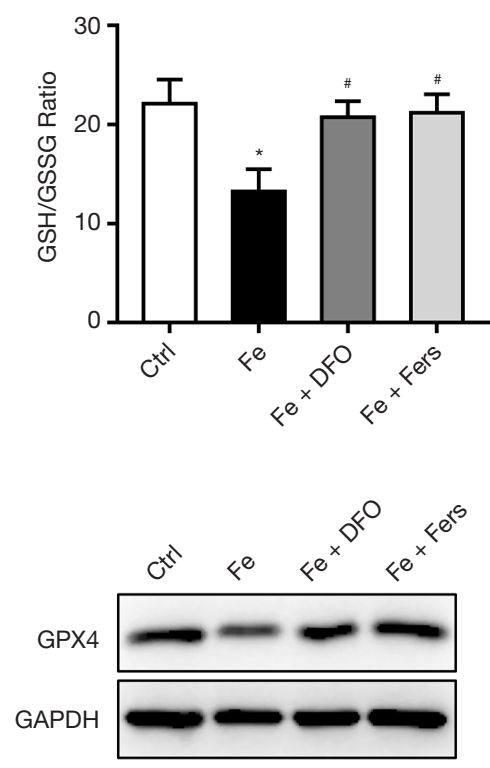

B
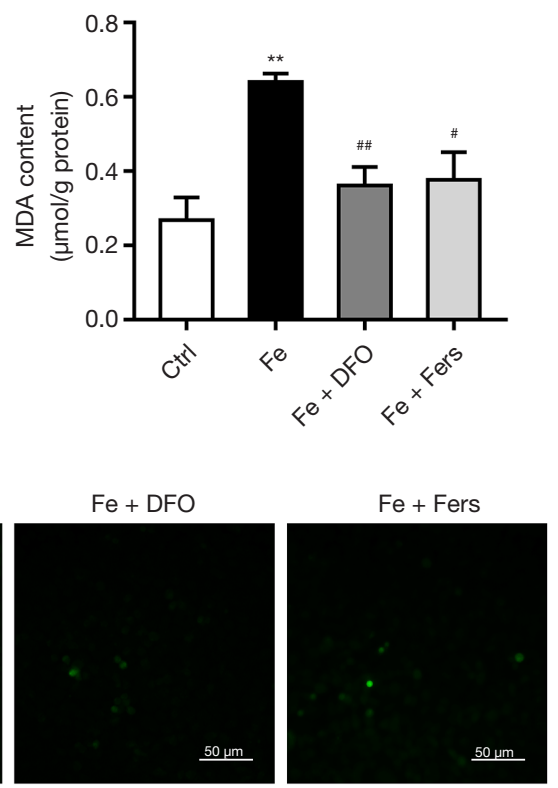

$E$
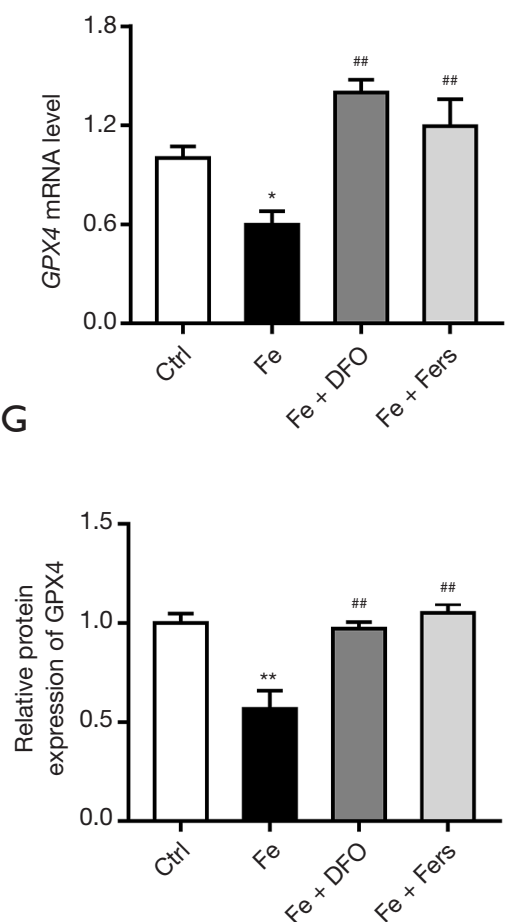

Figure 6 Iron participates in the occurrence of cell calcification by inducing ferroptosis. (A) Image-i $\mathrm{T}^{\circledR}$ Lipid Peroxidation Kit detects the lipid peroxidation in cells. (B) The MDA Detection Kit (Beyotime Institute of Biotechnology, Jiangsu, China) detects the level of superoxide lipid in cells. (C) ROS detection kit to detect intracellular ROS levels (×200). (D) GSH/GSSG detection kit to detect changes in the ratio of GSH/GSSG; (E) GPX4 mRNA expression (F,G) GPX4 protein expression. Ctrl: cells without any treatment; Fe: $100 \mu \mathrm{M} \mathrm{FeSO}{ }_{4}$ treated cells; $\mathrm{Fe}$ + DFO: $100 \mu \mathrm{M} \mathrm{FeSO}$ + iron chelator treated cells; Fe + Fers: $100 \mu \mathrm{M} \mathrm{FeSO}_{4}$ + ferroptosis inhibitor ferrostatin treated cells. *, compared with Ctrl, $\mathrm{P}<0.05$; **, compared with Ctrl, $\mathrm{P}<0.001$; ", compared with $\mathrm{Fe}, \mathrm{P}<0.05$; ; , compared with $\mathrm{Fe}, \mathrm{P}<0.001$. GSH/GSSG, glutathione/glutathione disulfide; GPX4, glutathione peroxidase; MDA, malondialdehyde; ROS, reactive oxygen species. 
it has been recognized that endothelial cells also play an important role in the formation of calcification (21). Studies have found that endothelial cells can participate in vascular calcification through EndMT. This process involves the TGF- $\beta$ signaling pathway, the Wnt signaling pathway, and the Notch signaling pathway and is related to inflammation and hypoxia (35). Endothelial cells also participate in vascular calcification through autocrine or paracrine action, including hydrogen sulfide $\left(\mathrm{H}_{2} \mathrm{~S}\right)$, nitric oxide $(\mathrm{NO})$, carbon monoxide (CO), and small active peptides (36). In addition, extracellular particles derived from endothelial cells are also involved in the process of vascular calcification (37).

Iron overload is divided into idiopathic and secondary overload (38). Idiopathic iron overload is a congenital metabolic disorder that leads to excessive iron accumulation in the body and is an autosomal recessive genetic disease. Secondary iron overload is often caused by massive blood transfusions, long-term oral iron, chronic alcohol addiction, ingestion of iron-containing diets, and certain blood diseases (38). Iron overload often leads to liver cirrhosis, impaired myocardial function, renal tubular damage, diabetes, impaired hematopoietic function, arthritis, osteoporosis, muscle atrophy, and skin pigmentation (39). Iron overload is closely related to atherosclerosis $(40,41)$. However, there are few studies on the relationship with vascular calcification. Nonetheless, vascular calcification is also a manifestation of atherosclerosis (33). Our research results proved that in addition to the above-mentioned adverse effects, iron overload can affect iron homeostasis and cause endothelial cell calcification. In our study, we found that iron overload increase iron deposition in endothelial cell, increased the expression levels of ferritin and decreased the expression levels of DMT. Ferritin is an iron-storage protein, and DMT is one protein participate in transport iron into cell. The expression changes of ferritin and DMT in endothelial cells suggest that the cells might attempt to reduce intracellular iron intake, which is similar to the results of Hou et al.'s study in human periodontal ligament cells (42). Furthermore, our results show that iron overload can participate in endothelial cell calcification in two ways. One way is that iron overload can promote endothelial cell apoptosis, which leads to endothelial calcification. Studies have found that in the early stage of cardiovascular endothelial calcification, cell apoptosis occurs, including apoptosis of mesenchymal cells, apoptosis of endothelial cells, and apoptosis of VSMCs $(21,43,44)$. Moreover, vascular calcification may be closely related to the apoptotic bodies released during cell apoptosis
(43-45). The other way is to participate in endothelial cell calcification by inducing cell ferroptosis. Ferroptosis is a new type of cell death that is different from apoptosis and necrosis. It is manifested as liposome peroxidation of the polyunsaturated fatty acids highly expressed on the cell membrane under the action of divalent iron, and it thereby induces cell death (18). Studies have shown that ferroptosis may be related to the calcification of VSMCs (46). The relationship with endothelial cell calcification has not yet been studied, and our results confirm for the first time that ferroptosis is involved in the process of endothelial cell calcification.

Based on the current research results, we believe that for patients at high risk of iron overload, attention should be paid to monitoring the possibility of iron overload. At the same time, necessary measures should be taken to reduce the chance of iatrogenic iron overload. For patients who receive unavoidable iron therapy, the risk of cardiovascular disease in these patients should be actively assessed. For patients who already have vascular calcification and must receive iron therapy, specific preventive measures should be considered to reduce the occurrence of adverse cardiovascular events.

The shortcomings of this study should be mentioned. Although this study initially revealed the effects and mechanisms of iron overload on endothelial cell apoptosis, ferroptosis, and calcification, it did not specifically analyze the signal transduction mechanism, and it is still not clear through which signaling pathway iron overload causes endothelial cell apoptosis and calcification. Subsequent studies should use the results of this study to further explore the influence of iron overload on possible signaling pathways and its relationship with endothelial cell apoptosis and calcification. At the same time, the results can also be used in conjunction with clinical cases to analyze the relationship between actual iron overload in different patients and vascular calcification, as well as the relationship with adverse events during long-term follow up.

\section{Acknowledgments}

Funding: This work was supported by a grant from the Tianjin Haihe Medical Scholars Fund.

\section{Footnote}

Reporting Checklist: The authors have completed the MDAR checklist. Available at https://dx.doi.org/10.21037/atm-21-5666 
Data Sharing Statement: Available at https://dx.doi. org/10.21037/atm-21-5666

Conflicts of Interest: All authors have completed the ICMJE uniform disclosure form (available at https://dx.doi. org/10.21037/atm-21-5666). All authors report that this work was supported by a grant from the Tianjin Haihe Medical Scholars Fund.The authors have no other conflicts of interest to declare.

Ethical Statement: The authors are accountable for all aspects of the work in ensuring that questions related to the accuracy or integrity of any part of the work are appropriately investigated and resolved.

Open Access Statement: This is an Open Access article distributed in accordance with the Creative Commons Attribution-NonCommercial-NoDerivs 4.0 International License (CC BY-NC-ND 4.0), which permits the noncommercial replication and distribution of the article with the strict proviso that no changes or edits are made and the original work is properly cited (including links to both the formal publication through the relevant DOI and the license). See: https://creativecommons.org/licenses/by-nc-nd/4.0/.

\section{References}

1. Chen Y, Zhao X, Wu H. Arterial Stiffness: A Focus on Vascular Calcification and Its Link to Bone Mineralization. Arterioscler Thromb Vasc Biol 2020;40:1078-93.

2. Raggi $\mathrm{P}, \mathrm{O}^{\prime} \mathrm{Neill}$ WC. Imaging for Vascular Calcification. Semin Dial 2017;30:347-52.

3. Mori H, Torii S, Kutyna M, et al. Coronary Artery Calcification and its Progression: What Does it Really Mean? JACC Cardiovasc Imaging 2018;11:127-42.

4. Rocha-Singh KJ, Zeller T, Jaff MR. Peripheral arterial calcification: prevalence, mechanism, detection, and clinical implications. Catheter Cardiovasc Interv 2014;83:E212-20.

5. Pawade T, Sheth T, Guzzetti E, et al. Why and How to Measure Aortic Valve Calcification in Patients With Aortic Stenosis. JACC Cardiovasc Imaging 2019;12:1835-48.

6. Chen J, Budoff MJ, Reilly MP, et al. Coronary Artery Calcification and Risk of Cardiovascular Disease and Death Among Patients With Chronic Kidney Disease. JAMA Cardiol 2017;2:635-43.

7. Rifkin DE, Ix JH, Wassel CL, et al. Renal artery calcification and mortality among clinically asymptomatic adults. J Am Coll Cardiol 2012;60:1079-85.

8. Lee SJ, Lee IK, Jeon JH. Vascular Calcification-New Insights Into Its Mechanism. Int J Mol Sci 2020;21:2685.

9. Kawada S, Nagasawa Y, Kawabe M, et al. Iron-induced calcification in human aortic vascular smooth muscle cells through interleukin-24 (IL-24), with/without TNF-alpha. Sci Rep 2018;8:658.

10. Mizuiri S, Nishizawa Y, Doi T, et al. Iron, coronary artery calcification, and mortality in patients undergoing hemodialysis. Ren Fail 2021;43:371-80.

11. Dixon SJ, Stockwell BR. The role of iron and reactive oxygen species in cell death. Nat Chem Biol 2014;10:9-17.

12. Singh N, Haldar S, Tripathi AK, et al. Brain iron homeostasis: from molecular mechanisms to clinical significance and therapeutic opportunities. Antioxid Redox Signal 2014;20:1324-63.

13. Fillebeen C, Charlebois E, Wagner J, et al. Transferrin receptor 1 controls systemic iron homeostasis by finetuning hepcidin expression to hepatocellular iron load. Blood 2019;133:344-55.

14. Ohgami RS, Campagna DR, Greer EL, et al. Identification of a ferrireductase required for efficient transferrindependent iron uptake in erythroid cells. Nat Genet 2005;37:1264-9.

15. Sousa L, Oliveira MM, Pessôa MTC, et al. Iron overload: Effects on cellular biochemistry. Clin Chim Acta 2020;504:180-9.

16. Jiang $\mathrm{X}$, Wang H, Shi W, et al. Hyperinsulinemia induces hepatic iron overload by increasing liver TFR1 via the PI3K/IRP2 pathway. J Mol Endocrinol 2014;53:381-92.

17. Cui R, Choi SE, Kim TH, et al. Iron overload by transferrin receptor protein 1 regulation plays an important role in palmitate-induced insulin resistance in human skeletal muscle cells. FASEB J 2019;33:1771-86.

18. Stockwell BR, Friedmann Angeli JP, Bayir H, et al. Ferroptosis: A Regulated Cell Death Nexus Linking Metabolism, Redox Biology, and Disease. Cell 2017;171:273-85.

19. Laguna-Fernandez A, Carracedo M, Jeanson G, et al. Iron alters valvular interstitial cell function and is associated with calcification in aortic stenosis. Eur Heart J 2016;37:3532-5.

20. Sánchez-Duffhues G, García de Vinuesa A, van de Pol V, et al. Inflammation induces endothelial-to-mesenchymal transition and promotes vascular calcification through downregulation of BMPR2. J Pathol 2019;247:333-46.

21. Yuan C, Ni L, Zhang C, et al. Vascular calcification: 
New insights into endothelial cells. Microvasc Res 2021;134:104105.

22. de Oliveira Sá MPB, Cavalcanti LRP, Perazzo ÁM, et al. Calcific Aortic Valve Stenosis and Atherosclerotic Calcification. Curr Atheroscler Rep 2020;22:2.

23. Nelson AJ, Raggi P, Wolf M, et al. Targeting Vascular Calcification in Chronic Kidney Disease. JACC Basic Transl Sci 2020;5:398-412.

24. Bourantas CV, Zhang YJ, Garg S, et al. Prognostic implications of coronary calcification in patients with obstructive coronary artery disease treated by percutaneous coronary intervention: a patient-level pooled analysis of 7 contemporary stent trials. Heart 2014;100:1158-64.

25. Hendriks EJ, Beulens JW, de Jong PA, et al. Calcification of the splenic, iliac, and breast arteries and risk of allcause and cardiovascular mortality. Atherosclerosis 2017;259:120-7.

26. Niu Q, Zhao H, Wu B, et al. Abdominal aortic calcification is superior to other arteries calcification in predicting the mortality in peritoneal dialysis patients - a 8 years cohort study. BMC Nephrol 2019;20:439.

27. Leening MJ, Elias-Smale SE, Kavousi M, et al. Coronary calcification and the risk of heart failure in the elderly: the Rotterdam Study. JACC Cardiovasc Imaging 2012;5:874-80.

28. Kälsch H, Lehmann N, Berg MH, et al. Coronary artery calcification outperforms thoracic aortic calcification for the prediction of myocardial infarction and all-cause mortality: the Heinz Nixdorf Recall Study. Eur J Prev Cardiol 2014;21:1163-70.

29. Matsumura K, Otagaki M, Fujii K, et al. Coronary artery calcification as a novel predictive marker of unstable coronary lesion in survivors of out-of-hospital cardiac arrest without ST-segment elevation. Resuscitation 2020;147:67-72.

30. Falk E. Pathogenesis of atherosclerosis. J Am Coll Cardiol 2006;47:C7-12.

31. Wolf D, Ley K. Immunity and Inflammation in Atherosclerosis. Circ Res 2019;124:315-27.

32. Basatemur GL, Jørgensen HF, Clarke MCH, et al. Vascular smooth muscle cells in atherosclerosis. Nat Rev Cardiol 2019;16:727-44.

33. Doherty TM, Asotra K, Fitzpatrick LA, et al. Calcification in atherosclerosis: bone biology and chronic inflammation at the arterial crossroads. Proc Natl Acad Sci U S A 2003;100:11201-6.

34. Durham AL, Speer MY, Scatena M, et al. Role of smooth muscle cells in vascular calcification: implications in atherosclerosis and arterial stiffness. Cardiovasc Res
2018;114:590-600.

35. Souilhol C, Harmsen MC, Evans PC, et al. Endothelialmesenchymal transition in atherosclerosis. Cardiovasc Res 2018;114:565-77.

36. Krüger-Genge A, Blocki A, Franke RP, et al. Vascular Endothelial Cell Biology: An Update. Int J Mol Sci 2019;20:4411.

37. Alique M, Ramírez-Carracedo R, Bodega G, et al. Senescent Microvesicles: A Novel Advance in Molecular Mechanisms of Atherosclerotic Calcification. Int J Mol Sci 2018;19:2003.

38. Siah CW, Trinder D, Olynyk JK. Iron overload. Clin Chim Acta 2005;358:24-36.

39. Brissot P, Troadec MB, Loréal O, et al. Pathophysiology and classification of iron overload diseases; update 2018. Transfus Clin Biol 2019;26:80-8.

40. Kraml P. The role of iron in the pathogenesis of atherosclerosis. Physiol Res 2017;66:S55-67.

41. Cornelissen A, Guo L, Sakamoto A, et al. New insights into the role of iron in inflammation and atherosclerosis. EBioMedicine 2019;47:598-606.

42. Hou J, Yamada S, Kajikawa T, et al. Iron plays a key role in the cytodifferentiation of human periodontal ligament cells. J Periodontal Res 2014;49:260-7.

43. Hutcheson JD, Venkataraman R, Baudenbacher FJ, et al. Intracellular $\mathrm{Ca}(2+)$ accumulation is strain-dependent and correlates with apoptosis in aortic valve fibroblasts. J Biomech 2012;45:888-94.

44. Proudfoot D, Skepper JN, Hegyi L, et al. Apoptosis regulates human vascular calcification in vitro: evidence for initiation of vascular calcification by apoptotic bodies. Circ Res 2000;87:1055-62.

45. Abbasian N. Vascular Calcification Mechanisms: Updates and Renewed Insight into Signaling Pathways Involved in High Phosphate-Mediated Vascular Smooth Muscle Cell Calcification. Biomedicines 2021;9:804.

46. Ma WQ, Sun XJ, Zhu Y, et al. Metformin attenuates hyperlipidaemia-associated vascular calcification through anti-ferroptotic effects. Free Radic Biol Med 2021;165:229-42.

(English Language Editor: B. Merser)

Cite this article as: Zhao L, Yang N, Song Y, Si H, Qin Q, Guo Z. Effect of iron overload on endothelial cell calcification and its mechanism. Ann Transl Med 2021;9(22):1658. doi: 10.21037/atm-21-5666 